\title{
Race and Menarche: A Study on Racial Subgroups Living in the West of Iran
}

\author{
Ali Ghanbari, PhD', Telka Noormohamadi, MD², Pegah Mirzapur, MSc ${ }^{1}$ and Mohammad Rasool \\ Khazaei, PhD $^{1^{*}}$
}

${ }^{1}$ Fertility and Infertility Research Center, Kermanshah University of Medical Sciences, Iran

${ }^{2}$ Student Research Committee, Kermanshah University of Medical Sciences, Iran

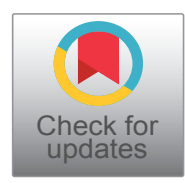

*Corresponding author: Mohammad Rasool Khazaei, PhD, Fertility and Infertility Research Center, Kermanshah University of Medical Sciences, Kermanshah, P.O. Box 1568, Iran, Tel: +98-83-34281563

\begin{abstract}
Objective: Menarche is a physiological phenomenon and significant mile stone in the life of a women and the age at menarche is an indicator of racial, geographical and nutritional patterns of different societies. The aim of present study was to determine the age at menarche in Kermanshah city in the west of Iran focusing on the effect of population racial subgroups living this city.

Materials and methods: This cross-sectional study conducted on 700 girls aged 12-15 year old's in the Kermanshah city, in the west of Iran. In this research, the age at menarche, as the main variable, was determined for each racial subgroup and compared between different variables. Statistical analyses were performed by one-way ANOVA and Tukey tests were performed to determine the statistical significance.
\end{abstract}

Results: The average age of first menstruation was $11.85 \pm$ 0.03 -years in the Kermanshah city. This age was inversely related to body mass index (BMI), weight, wrist circumference and racial subgroups. The menarche age in this city is influenced by ethnicity, socioeconomic and climate, and has reduced in the past decade. Also, it may be stated that social well-being and nutritional standards have improved in the city.

Conclusion: The average age at menarche in the Kermanshah city (a cold area) is higher than warmer regions in Iran; it may be more influenced by the race than the climate.

\section{Keywords}

Menarche, Body Mass Index, Race Relation, Iran

\section{Introduction}

Menarche is the most important events in the wom- en's lives. The cultural, social, and epidemiological patterns of this biological incident has led many epidemiological researches to study this phenomenon and the factors affecting it [1]. Early or late onset of menarche can caused some morbidity or diseases in women's lives over the coming years [2]. For example, the effects of early menarche (before age 12) include short stature [3,4]; obesity [5], type II diabetes; cardiovascular diseases; hypertension; breast, endometrial, and ovarian cancers; and increase of mental and behavioral disorders (such as smoking, eating disorders alcohol use, depression, unsafe sex, and early pregnancy in adolescence) $[6,7]$ and a late menarche (after 16-years) may lead to osteoporosis, depression, and social anxiety disorder in the coming years of life [6].

Age at menarche is influenced by genetic and environmental factors. Many studies show similarity in the age at menarche between sisters [8], twins [9], mother and daughters [10] that emphasis the influence of genetics factors. Although, these factors are seem to be a basically effect for predicting menarche age, other factors like geographical living zone, the time exposing to sun shine, public health, nutritional pattern and also psychological ingredients also could affect the timing of menarche [11].

Mean age at menarche differs in various parts of the world. Age at menarche of girls in various countries or even between different races varies, but the reasons of these changes are not yet well known [12]. These days,

Citation: Ghanbari A, Noormohamadi T, Mirzapur P, Khazaei MR (2019) Race and Menarche: A Study on Racial Subgroups Living in the West of Iran. Reprod Med Int 2:011. doi.org/10.23937/26434555/1710011

Accepted: May 23, 2019; Published: May 25, 2019

Copyright: (C) 2019 Ghanbari A, et al. This is an open-access article distributed under the terms of the Creative Commons Attribution License, which permits unrestricted use, distribution, and reproduction in any medium, provided the original author and source are credited. 
the age at menarche is been reduced by development of nutrition and public health [11], citizenship [13] in the countries. Furthermore, development of nutrition and socio-economic condition caused 2-3 months reduction of menarche age in each decade from $19^{\text {th }}$ century up to now. In the middle of $19^{\text {th }}$ century, the age at menarche was 17-years in United States and Scandinavia and 15-years in France [14] but it was changed to 12.7-years in United States [11].

Age at menarche among developing countries also is been reduced comparing $19^{\text {th }}$ century of developed countries and is 12.8 in Turkey [15] and 14-years in Egypt [16]. Although, in Iran some studies have been estimated age at menarche, considering changing this age after decades and also the importance of age at menarche as an index for evaluating public health of society, the present study was designed in Kermanshah city in the west of Iran. The study aimed to characterize the age at menarche in Kermanshah focusing the effect of population racial subgroups living this city.

\section{Material and Methods}

This cross-sectional study carried out on 700 girls aged 12-15-years who were students of national high schools in Kermanshah, west of Iran in 2011. The study was approved by the ethical committee of Kermanshah University of Medical Sciences with the project code of 89164.

Considering the objectives of the study, we used age at menarche, the main variable, as the basis for calculating the sample volume. Using a confidence coefficient of $95 \%$ and accuracy of 0.5 , the sample volume was calculated. Cluster sampling was performed in the city based on the number of girls of the desired age range.

A questionnaire was designed and verified for validity and reliability by researchers. A briefing class was held for people in charge of distributing the questionnaires to ensure homogeneity. The oral questionnaires were submitted to the people in study. Those girls with hormonal disorders, anemia and chronic infections such as tuberculosis and major thalassemia were excluded from the study. The oral questionnaire contained questions about the following issues: date of birth, age of first menstruation, weight, height and the race. The racial subgroups were considered for three previous generations that the girl belongs to. Also the wrist circumference, hip circumference were measured.

The body mass index was calculated using the equation $\mathrm{BMI}=$ Weight $(\mathrm{kg}) /$ Height $^{2}\left(\mathrm{~m}^{2}\right)$ [4]. The samples were divided into 5 categories: Below 15; 15.1-20; 20.125, 25.1-30; and above 30.

\section{Statistical Analysis}

Data were analyzed using one-way analysis of variance with SPSS version 16.0 software, and $p<0.05$ was considered significant.

\section{Results}

The mean of age at menarche was $11.85 \pm 0.03$, and the highest age was for Kurds $(11.95 \pm 0.91)$ and the lowest age for Lors $(11.5 \pm 0.82)$ racial subgroups (Table 1).

Wrist circumference $(P<0.05)$ and $B M I(P<0.01)$ was two anthropometric dimensions that showed relationship with age at menarche, but there were no relationship between Hip circumference, Waist circumference, weight, height and age at menarche. The study showed correlation between the racial subgroups with age at menarche $(P<0.05)$. In other words, the age at menarche is different among racial subgroups living in Kermanshah city (Table 2).

\section{Discussion}

The mean age at menarche in Kermanshah city was $11.85 \pm 0.03$, and it was same as Markazi province of Iran. To date, in Iran the lowest ages at menarche is reported in Sari city $(11.4 \pm 1.1)$ at north [17] and the highest in Birjand at east north of country $(13.8 \pm 1.6)$ [18]. The mean age at menarche in Kermanshah city was lower than undeveloped countries (mostly in Africa) and was as high as developed countries [19].

However, development of socioeconomic conditions could not be considered as the only influential factor on

Table 1: Distributions of racial subgroup in a sampled population of Kermanshah city (West of Iran).

\begin{tabular}{|c|c|c|c|c|}
\hline Racial subgroups & Number & Percent & Mean age at menarche & S.E.M \\
\hline Kurd & 327 & 46.7 & 11.95 & 0.91 \\
\hline Turk & 40 & 5.7 & 11.94 & 1.00 \\
\hline Lor & 36 & 5.1 & 11.50 & 0.82 \\
\hline Fars & 266 & 38 & 11.70 & 0.92 \\
\hline Others & 31 & 4.4 & 11.77 & 0.92 \\
\hline
\end{tabular}

Table 2: Correlation of anthropometric dimensions and racial factor with age at menarche in a sampled population of Kermanshah city.

\begin{tabular}{|l|l|l|l|l|l|l|l|}
\hline & Racial subgroups & H. C & Wa. C & Wr. C & W & H & BMI \\
\hline Age at menarche & $-0.097^{*}$ & -0.064 & -0.074 & $-0.096^{*}$ & -0.051 & 0.052 & $-0.099^{* *}$ \\
\hline
\end{tabular}


the age at menarche. In which, two developed countries of Germany (14-years), Czech Republic (14.6-years) was higher than undeveloped country such as Congo-Brazzaville (12-years) [1]. Furthermore, the age at menarche differs through racial subgroups of three racial groups and in the case of United States, because of intermingle of the races, the pattern of age at menarche is differs from other part of the world [19].

Important characteristics of women reproductive age is menarche. Increase or decrease of reproductive period will influence fertility, socioeconomic and population indices. It's important as an indicator of public health, disease and puberty health. According to Frisch's theory which states that menstruation occurs when body attains the critical mass of $48 \mathrm{~kg}$ or when body fat increases from $16 \%$ to $23 \%$, the findings of our study corroborate this theory by showing correlation body mass index to age at menarche be [20]. This idea may express the differences in the age at menarche besides on the studies which emphasized the influence of climate and socioeconomics only.

Other Studies showed that in iran (Ahvaz city) the mean age at menarche was $11.86 \pm 1.07$-years, which correlate with height, weight, and had an inverse association with body mass index [21]. Even living in the city and the rural areas affects the age of the menarche. A study among female adolescents aged 12-19-years in a rural area of Bangladesh showed that the age at menarche related to seasons, and association with marital and nutritional status. In rural population, the age at menarche was lower than urban region estimation (13.0-years) in Bangladesh [22].

Moreover, a study on pattern of menarche in cold Azari regions of northwestern of Iran is consistent with southern, eastern and some central regions of Iran which have warm climate. In other words, although the climate to be influential on the age at menarche, and mountainous cold climates have higher ages of menarche, the ethnicity has more effective that can be seen in Azari racial subgroup of Iranian population [23]. In this regards, we can say that although climate of Kermanshah is constant for the all its population, the influence of ethnic induces differences in the age at menarche that was shown in present study. In this study the age at menarche in girls of different regions of Iran varies in view of the geographical and indigenous characteristics of each region. The mean age of menarche in the two studied periods (1990) was $13.86 \pm 1.51$ and $13 / 65 \pm 1.47$ respectively, at the time of study, the mean age of menarche was significantly lower in urban areas than in rural areas, but after nine years (1999), the decline of the age of the menarche was seen in urban and rural areas [23].

Finally, considering society development as a factor affecting age at menarche, we could say that public health of Kermanshah city is may developed according a study done by Keshavarzi and colleagues 10-years ago that shown the age at menarche was 13.4-years for this city [24].

In conclusion, the menarche age in Kermanshah city is shifting down, consistent with developed countries during last decades, and the pattern of age at menarche is influenced by BMI and ethnicity and the climate and socioeconomics could be considered as the secondary factors.

\section{Acknowledgements}

This work is derived from a M.D thesis (89164) in Kermanshah University of Medical Sciences.

\section{Conflict of Interest}

There is no conflict of interest in this study.

\section{References}

1. Thomas F, Renaud F, Benefice E, de Meeus T, Guegan JF (2001) International variability of ages at menarche and menopause: Patterns and main determinants. Hum Biol 73 : 271-290.

2. Bahrami N, Soleimani MA, Chan YH, Ghojazadeh $M$, Mirmiran P (2014) Menarcheage in Iran: A meta-analysis. Iran J Nurs Midwifery Re 19: 444-450.

3. Onland-Moret $\mathrm{NC}$, Peeters $\mathrm{PH}$, van Gils $\mathrm{CH}$, ClavelChapelon F, Key T, et al. (2005) Age at menarche in relation to adult height: The EPIC study. Am J Epidemiol 162: 623-632.

4. Berkey CS, Gardner JD, Frazier AL, Colditz GA (2000) Relation of childhood diet and body size to menarche and adolescent growth in girls. Am J Epidemiol 152: 446-452.

5. Freedman DS, Khan LK, Serdula MK, Dietz WH, SrinivasanSR, et al. (2003) The relation of menarcheal age to obesity in childhood and adulthood: The Bogalusa heart study. BMC Pediatr 3: 3.

6. Karapanou O, Papadimitriou A (2010) Determinants of menarche. Reprod Biol Endocrinol 8: 115.

7. Golub MS, Collman GW, Foster PM, Kimmel CA, RajpertDe Meyts E, et al. (2008) Public health implications of altered puberty timing. Pediatrics 3: S218-S230.

8. Reymert ML, Jost H (1947) Further data concerning normal variability of menstrual cycle during adolescence and factors associated with age at menarche. Child Dev 18: 169-179.

9. Loesch DZ, Huggins R, Rogucka E, Hoang NH, Hopper JL (1995) Genetic correlates of menarcheal age: A multivariate twin study. Ann Hum Biol 22: 479-490.

10. Campbell BC, Udry JR (1995) Stress and age at menarche of mothers and daughters. J Biosoc Sci 27: 127-134.

11. Ghazi B (1995) Clinical gynecology endocrinology and infertility translation. ( $7^{\text {th }}$ edn), Tehran, Golban.

12. Ong KK, Ahmed ML, Dunger DB (2006) Lessons from large population studies on timing and tempo of puberty (secular trends and relation to body size): The European trend. Mol Cell Endocrinol 254-255: 8-12.

13. Graham MJ, Larsen U, Xu X (1999) Secular trend in age at menarche in China: A case study of two rural counties in Anhui Province. J Biosoc Sci 31: 257-267. 
14. Bieber EJ, Sanfilippo JS, IR H (2006) Clinical Gynecology. Churchil-Livingston, New York.

15. Ersoy B, Balkan C, Gunay T, Onag A, Egemen A (2004) Effects of different socioeconomic conditions on menarche in Turkish female students. Early Hum Dev 76: 115-125.

16. Torres-Mejia G, Cupul-Uicab LA, Allen B, Galal O, SalazarMartinez E, et al. (2005) Comparative study of correlates of early age at menarche among Mexican and Egyptian adolescents. Am J Hum Biol 17: 654-658.

17. Akhi O, Timourzadeh M, Kashi Z, Kowsarian M (2008) A Study on 6-18 years-old girl students about weight and height in Sari. J Mazandaran Univ Med Sci 18: 50-57.

18. Naseh N, Hedayati H, Ataei M, Jahani N (2009) The prevalence of menstrual disturbances in Birjand University of Medical Sciences students. Mod Care J 5: 32-39.

19. Bayat PD, Ghanbari A, Khazaei M, Ghorbani R, Amiri S (2012) Age at menarche and related factors in girls of urban areas of Markazi (Central) Province of Iran. Int J Morphol 30: 15-18.
20. Speroff L, Fritz M (2011) Clinical gynecologic endocrinology and infertility. ( $8^{\text {th }}$ edn), Lippincot Williams and Wilkins, Philadelphia, USA.

21. Sharifi N, Najar S, Tadaunnajaf M, Haghighizadeh M (2013) Relationship between some anthropometric indices and menarche age among girls in Ahvaz city. Scientific Journal of Ilam University of Medical Sciences (persian) 22: 50-55.

22. Rah JH, Shamim AA, Arju UT, Labrique AB, Rashid M, et al. (2009) Age of Onset, Nutritional Determinants, and Seasonal Variations in Menarche in Rural Bangladesh. J Health Popul Nutr 27: 802-807.

23. Kazem M, Zeraati H, Majdzadeh R, Karimlo M (2006) Evaluating the trend of change in the mean onset age of menarche in Iranian girls. Journal of Reproduction \& Infertility 6: 523-530.

24. Keshavarzi F, Azadbar M (2001) Study of age at menarche and its correlation with height, weight and socioeconomic condition in guidance schools in Kermanshah city. J Kurd $U$ Med Sc 20: 23-26. 